This item is the archived peer-reviewed author-version of:

\title{
The ligaments of the canine hip joint revisited
}

\section{Reference:}

Casteleyn Christophe, de Ouden I., Coopman F., Verhoeven G., Van Cruchten Steven, van Ginneken Christa, Van Ryssen B., Simoens P..- The ligaments of the canine hip joint revisited

Anatomia, histologia, embryologia: journal of veterinary medicine: series C - ISSN 0340-2096 - 44:6(2015), p. 433-440

Full text (Publishers DOI): http://dx.doi.org/doi:10.1111/ahe.12155

To cite this reference: http://hdl.handle.net/10067/1286100151162165141 
1 The ligaments of the canine hip joint revisited

2

3 C. Casteleyn ${ }^{1 *}$, I. den Ouden ${ }^{2}$, F. Coopman ${ }^{3}$, G. Verhoeven ${ }^{4}$, S. Van Cruchten ${ }^{1}$, C.

$4 \quad$ Van Ginneken $^{1}$, B. Van Ryssen ${ }^{4}$, P. Simoens ${ }^{2}$

5

$6{ }^{1}$ Laboratory of Applied Veterinary Morphology, Faculty of Pharmaceutical, Biomedical

7 and Veterinary Sciences, University of Antwerp, Universiteitsplein 1, B-2610 Wilrijk,

8 Belgium

$9{ }^{2}$ Department of Morphology, Faculty of Veterinary Medicine, Ghent University,

10 Salisburylaan 133, B-9820 Merelbeke, Belgium

$11{ }^{3}$ Department of Applied Biosciences, Faculty of Bioscience Engineering, Ghent

12 University, Valentin Vaerwijckweg 1, B-9000 Gent, Belgium

$13{ }^{4}$ Department of Veterinary Medical Imaging and Small Animal Orthopaedics, Faculty of

14 Veterinary Medicine, Ghent University, Salisburylaan 133, B-9820 Merelbeke, Belgium

$16 *$ Correspondence

17 Tel.: +32 3-265-28-21; fax: +32 3-265-24-33;

18 e-mail: christophe.casteleyn@uantwerpen.be

19

$20 \quad$ With 3 tables and 7 figures

22 Short title: Canine hip joint ligaments 


\section{Abstract}

25 Numerous conventional anatomical textbooks describe the canine hip joint, but many

26 contradictions, in particular regarding the ligament of the femoral head, are present. This

27 paper presents a brief overview of the different literature descriptions. These are

28 compared with own observations that have resulted in a revised description of the

29 anatomy of the ligament of the femoral head in the dog. To this purpose, the hip joints of

$3041 \mathrm{dogs}$, euthanized for reasons not related to this study and devoid of lesions related to

31 hip joint pathology, were examined. It was observed that the ligament of the femoral head

32 is not a single structure that attaches only to the acetabular fossa, as generally accepted,

33 but it also connects to the transverse acetabular ligament and is complemented by a

34 strong accessory ligament that courses in caudal direction to attach in the elongation of

35 the acetabular notch that extends on the cranioventral surface of the body of the ischium.

36 The description of this accessory ligament in conventional anatomical handbooks is

37 incomplete. This description of the accessory ligament of the femoral head could support

38 the research unravelling the etiopathogenesis of hip instability.

40 Key words: Canine hip joint; Acetabulum; Ligament of the femoral head; Transverse 41 ligament; Hip dysplasia 


\section{Introduction}

44 The canine hip joint (Articulatio coxae) is of major clinical importance since hip 45 dysplasia is a common orthopaedic disorder in the dog (Ginja et al., 2010). As a result, all 46 consulted conventional anatomical handbooks cover the anatomy of the hip joint.

47 However, the ligament of the femoral head, designated in official nomenclature as

48 Ligamentum capitis ossis femoris, a term to be preferred above the term round ligament

49 or Ligamentum teres femoris (World Association of Veterinary Anatomists, 2012), is

50 described ambiguously. The most straightforward descriptions reflect the general

51 knowledge that in domestic mammals this ligament is located inside the joint capsule and

52 connects the acetabular fossa (Fossa acetabuli) with the fovea of the femoral head (Fovea

53 capitis ossis femoris) (Zietzschmann, 1974; Sisson, 1975; Popesko, 1982; Anderson and

54 Anderson, 1994; Liebich and König, 2001; Salomon, 2005; Done et al., 2009; Dyce et al.,

55 2010). Other authors provide more detailed descriptions. According to Nickel et al.

56 (1986) and Liebich et al. (2004) the ligament of the femoral head originates in the

57 acetabular fossa and continues through the acetabular notch (Incisura acetabuli) to insert

58 in the fovea of the femoral head. Evans (1993) and Evans and deLahunta (1996) state that

59 branches of the ligament of the femoral head blend with the transverse acetabular

60 ligament (Ligamentum transversum acetabuli), resulting in a broad, fan-shaped

61 attachment to the acetabulum. Adams (2004) also described such fan-shaped formation of

62 the acetabular attachment. Barone (2000) mentions an accessory ligament, which runs in

63 the acetabular notch towards the transverse acetabular ligament and leaves the acetabular

64 notch at the cranial border. In contrast, Budras and Reese (2002) illustrate that the 
65 ligament of the femoral head proceeds in caudal direction through the acetabular notch to 66 attach to the pelvis outside the hip joint.

67 From this concise literature review it might be clear that many different descriptions, 68 resulting in contradictions and ambiguity, are present in literature. The ligament of the

69 femoral head is indeed a complex structure, as evidenced recently in a comparative study

70 by Canillas et al. (2011), who demonstrated that in various species, including amphibians,

71 reptiles, birds and mammals, this ligament shows most notable changes not only in its

72 insertions but also in the number of its bundles, while a fibrocartilaginous meniscoid

73 structure is present in the hip joint of various mammals including rats and cats. Since the

74 inaccurate descriptions of the complex ligament of the femoral head could hamper the

75 unravelling of the etiopathogenesis of canine hip joint pathologies, an anatomical study

76 was performed revisiting the canine hip joint. The aim of this paper is to describe the

77 anatomy of the ligament of the femoral head in great detail and to present morphometric

78 data on this ligament in different dog breeds.

79

80 Materials and methods

81 Animals

82 Forty-one dogs, euthanized for reasons other than this study and devoid of lesions related

83 to hip joint pathology, were included. Since the animals originated from different Flemish

84 animal shelters, no information of age was available. However, all dogs had permanent

85 dentition and appeared adult on visual inspection. Breed and weight are presented in

86 Table 1.

87 
89 The dogs were positioned in dorsal recumbency allowing the dissection of their hip joints

90 via a ventromedial approach. After removal of the joint capsule, the ligament of the

91 femoral head became visible and could be studied anatomically and morphometrically.

92 The transverse acetabular ligament was subsequently removed. Finally, the ligament of

93 the femoral head was meticulously excised to allow further morphometric analysis.

\section{Morphometric analysis}

96 The length of the ligament of the femoral head from its origin in the fovea of the femoral

97 head to its attachment in the acetabular fossa as well as the length of any accessory 98 ligament was determined using digital sliding callipers. In addition, the ligament of the

99 femoral head was excised and weighed, and its volume was determined by means of the

100 water displacement method. The correlation between the mean weights of the examined 101 dog breeds and the mean weights, volumes and lengths of their ligaments of the femoral 102 head as well as the lengths of the their accessory ligaments were calculated.

\section{Preparation of an arthrologic specimen}

105 An arthrologic specimen was prepared using a representative left hip joint. This specimen 106 contained the left femur and hip bone (Os coxae) connected by the ligament of the 107 femoral head and any additional ligaments under study. The majority of soft tissues 108 located outside the joint capsule were removed manually. The smaller tissue remnants 109 were then macerated by immersion in sodium hypochlorite $42^{\circ}$ (VWR International N.V.,

110 Leuven, Belgium) for approximately 15 minutes. Finally, the joint capsule was removed. 
111 After rinsing the arthrologic specimen with cold tap water it was bleached by immersion

112 in 10\% hydrogen peroxide (UNIVAR Benelux N.V., Brussels, Belgium) for three days.

113 The specimen was then rinced again and dried in a vented hood.

\section{Results}

\section{Anatomy of the ligament of the femoral head}

117 The ligament of the femoral head originated from the fovea of the femoral head and

118 contained a variable amount of adipose tissue. Its lateral segment, which inserted on the

119 fovea of the femoral head, was cylindrical and consisted of a single strand. The ligament

120 fanned out on its course towards the acetabulum to form multiple, partly fused fascicules

121 that attached to the acetabular fossa (Fig. 1), to the dorsal border of the transverse

122 acetabular ligament (Figs. 1 and 2) and to the origin of the caudal elongation of the

123 acetabular notch that extends on the cranioventral surface of the body of the ischium,

124 without breaching the acetabular contour nor the joint capsule (Fig. 3).

125 In all examined hip joints, an additional strong strand branched off from the ligament of

126 the femoral head and coursed in caudal direction through the acetabular notch. This

127 accessory ligament broke through the joint capsule to fill the entire caudal elongation of

128 the acetabular notch. As such, it was easily recognized as a separate ligament. In most

129 cases, the accessory ligament was attached to the transverse acetabular ligament when it

130 crossed the latter (Figs. 4 and 5).

131 In five dogs, the accessory ligament of either hip joint ran to and inserted on the cranial

132 extremity of the transverse acetabular ligament. It then continued in the acetabular notch

133 to attach to its caudal elongation. The accessory ligament was located parallel and 
134 dorsomedial to the transverse acetabular ligament, but could be separated from the latter 135 (Fig. 5).

136 In one dog the accessory ligament of either hip joint could be distinctly separated from

137 the transverse acetabular ligament, since the ligament of the femoral head showed no

138 attachment to the transverse acetabular ligament (Fig. 6).

139 The arthrologic specimen that was prepared from a representative joint is shown in Fig. 7.

140 The specimen shows the typical branching pattern of the ligament of the femoral head,

141 including the accessory ligament which crosses the transverse acetabular ligament

142 dorsally, courses caudally in the groove formed by the caudal elongation of the acetabular

143 notch and attaches both in this bony groove and on the adjacent cranioventral surface of

144 the body of the ischium.

145

\section{Morphometric characteristics of the ligaments of the femoral head}

147 The weights, volumes and lengths of the ligaments of the femoral head in the various

148 breeds are shown in Table 2. The length of the accessory ligament, measured from its

149 origin from the ligament of the femoral head to its attachment on the ischium, is

150 presented in Table 3. The correlation coefficients ( $r$ ) were the following: $r$ (body weight,

151 ligament weight $)=0.91, \mathrm{r}($ body weight, ligament volume $)=0.91, \mathrm{r}($ body weight,

152 ligament length $)=0.45, \mathrm{r}($ body weight, accessory ligament length $)=0.66$.

\section{Discussion}

155 The typical configuration of the ligament of the femoral head, as presented in Fig. 7, has 156 not been described previously. In all but one of the examined dogs, the ligament attached 
157 to the transverse acetabular ligament before inserting in the acetabular fossa. Such

158 attachment has only been described by Evans (1993), while it was observed in the vast

159 majority of the dogs examined in the present study. The results further show that the

160 common English term for the ligament of the femoral head, i.e. round ligament, is

161 confusing since the ligament is only cylindrical at its origin in the fovea of the femoral

162 head and fans out to form multiple fascicules. The presence of an accessory ligament

163 branching off from the ligament of the femoral head and running in caudal direction to

164 attach to the pelvis outside the joint cavity has previously been illustrated solely by

165 Budras and Reese (2002).

166 Such an accessory ligament branching off from the ligament of the femoral head is not

167 mentioned in the Nomina Anatomica Veterinaria (World Association of Veterinary

168 Anatomists, 2012) and is therefore still innominate. Providing a name for this structure

169 would omit the need for extensive descriptions when referring to it. The Nomina

170 Anatomica Veterinaria (World Association of Veterinary Anatomists, 2012) stipulates

171 that new terms should be as short and simple as possible, but also instructive and

172 descriptive. A potential name could be Ligamentum accessorium capitis ossis femoris,

173 which is very descriptive in nature. However, this term should not be confused with the

174 Ligamentum accessorium ossis femoris that is only present in the horse and rabbit and

175 connects the fovea of the femoral head with the attachment of the straight abdominal

176 muscle to the prepubic tendon.

177 The ligament of the femoral head contained a variable amount of adipose tissue, which

178 might have interfered with the morphometric analysis since it was difficult to completely

179 remove the smaller fatty remnants. Only a few publications present data about the volume 
180 of the ligament of the femoral head in various breeds. Values ranging from 0.53 to 0.62

$181 \mathrm{~cm}^{3}$ have been published for the Labrador Retriever (Lust et al., 1980a; Lust and

182 Summers, 1981; Burton-Wurster et al., 1999). Mande and co-workers (2003) reported a

183 mean volume of $0.82 \mathrm{ml}$ in the German Shepherd Dog. In the present study, values of

$1840.59 \mathrm{~cm}^{3}$ and $0.90 \mathrm{~m}^{3}$ were measured in the Labrador Retriever and German Shepherd

185 Dog, respectively. Our values are thus comparable with literature data, although it is not

186 clear whether the accessory ligament of the femoral head was taken into account in the

187 cited studies. It is not surprising that the weight and volume of the ligament of the

188 femoral head correlate very well with the body weight $(r=0.91)$. In contrast, the length

189 of the ligament of the femoral head is far less positively correlated to body weight $(\mathrm{r}=$

190 0.45). The linear increase in the distance between the femoral head and the acetabular

191 fossa is not pronounced since widening of the joint cavity negatively affects joint stability

192 (Lust et al., 1980b).

193 A stronger correlation is present between the length of the accessory ligament and the

194 body weight $(r=0.66)$. The larger the breed, the longer is the accessory ligament.

195 However, since the accessory ligament inserts on the caudal elongation of the acetabular

196 notch that extends on the cranioventral side of the body of the ischium, its length is more

197 specifically related with pelvic length. The effect of age on the morphometry of the

198 ligaments of the hip joint was not determined in the present study since no data about the

199 ages of the dogs were available. However, since all dogs had a permanent dentition and

200 appeared fully-grown, they were considered to be adults.

201 Detailed anatomical knowledge of the ligaments associated with the hip joint is important

202 when studying the functionality of the articulation. Although the ligament of the femoral 
203 head is a well-known structure, its role of in the etiopathogenesis of canine hip dysplasia

204 is still to be elucidated. Arthroscopic examination of young dogs with hip dysplasia has

205 revealed partial or complete rupture of this ligament in $81 \%$ and $7 \%$ of cases, respectively

206 (Holsworth et al., 2005). A significant hypertrophy of the ligament of the femoral head,

207 characterized by elongation and thickening, has been observed in experimental cases of

208 hip dysplasia in growing dogs (Schoenecker et al., 1984). These two studies illustrate that

209 elongation of the ligament of the femoral head is associated with hip dysplasia. It is,

210 however, not known whether the elongation of the ligament of the femoral head is the

211 primary cause or a secondary effect of the developing pathology. It is hypothesized that

212 laxity of the fibrocartilagenous structures associated with the hip joint results in hip

213 instability which further develops to hip dysplasia.

214 Many authors agree that primary or secondary osteoarthritis also affects the integrity of

215 the ligament of the femoral head and might increase its volume (Lust et al., 1980; Lust

216 and Summers, 1981; Lust, 1997; Burton-Wurster et al., 1999; Clements et al., 2006).

217 Other reports, however, are contradictory (Mande et al., 2003).

218 Hip luxation as often seen in traffic accidents is another pathology that might affect the

219 ligaments of the canine hip joint (Jones, 1985). Since the ligament of the femoral head is

220 rather elastic, it can herewith elongate and potentially rupture (Salomon, 2005; Dyce et

221 al., 2010).

222 In analogy to the ligament of the femoral head, the role of the accessory ligament in the

223 biomechanical functioning of the hip joint is still enigmatic. It is hypothesized that the

224 articular structures of the hip have further developed during evolution to cope with the

225 more complex movements of the hip joint in higher species. Indeed, in amphibians and 
226 reptiles, the ligament of the femoral head is formed by a mere reinforcement of the dorsal

227 side of the joint capsule, while it appears first as a typical structure in birds (Canillas et

228 al., 2011). Furthermore, the number of fascicles of the ligament of the femoral head is

229 associated with the rotary movement of the hip (Canillas et al., 2011). As a result, it is

230 possible that the accessory ligament of the femoral head represents a further

231 reinforcement of the hip joint. Whether an underdeveloped accessory ligament lies at the

232 basis of hip laxity and dysplasia should be examined in future studies.

\section{Conclusions}

235 This work demonstrates that a strong accessory ligament is present in the canine hip joint

236 in addition to the well-known ligament of the femoral head. The variable representations

237 of the ligaments associated with the canine hip joint should be taken into account when

238 examining the hip joint by medical imaging or macroscopic inspection during surgery.

239 The detailed data presented here can be valuable in future studies unravelling the

240 etiopathogenesis of hip dysplasia and allow for using the appearance of the ligaments as a

241 diagnostic parameter.

\section{Conflict of interest statement}

244 None declared.

246 References

247 Adams, D. R., 2004: Musculoskeletal System. In: Canine Anatomy - A Systemic Study, 248 4th edn (Adams, D. R. ed). Ames: The Iowa State Press. 
Anderson, W. D., and B. G. Anderson, 1994: Limbs and Back. In: Atlas of Canine

250 Anatomy (Anderson, W. D., and B. G. Anderson eds). London: Lea \& Febiger.

251 Barone, R., 2000: Arthrology et Myologie. In: Anatomie Comparée des Mammifères

252 Domestiques, Tome 4, 4th edn (Barone, R. ed). Paris: Editions Vigot.

253 Budras, K. D., and S. Reese, 2002: Synovial Structures of the Pelvic Limb. In: Anatomy

254 of the Dog, 4th edn (Budras, K. D. ed). Hannover: Schlütersche.

255 Burton-Wurster, N., J. P. Farese, R. J. Todhunter, and G. Lust, 1999: Site-specific

256 variation in femoral head cartilage composition in dogs at high and low risk for

257 development of osteo-arthritis: insights into cartilage degeneration. Osteoarthritis

$258 \quad$ Cartilage 7, 486-497.

259 Canillas, F., M. J. Delgado-Martos, A. Touza, A. Escario, A. Martos-Rodriguez, and E.

260 Delgado-Baeza, 2011: An approach to comparative anatomy of the acetabulum from

261 amphibians to primates. Anat. Histol. Embryol., 40, 466-473.

262 Clements, D. N., S. D. Carter, J. F. Innes, and W. E. R. Ollier, 2006: Genetic basis of

263 secondary osteoarthritis in dogs with joint dysplasia. Am. J. Vet. Res. 67, 909-918.

264 Done, S. H., P. C. Goody, S. A. Evans, and N. C. Stickland, 2009: The Pelvis. In: Color

265 Atlas of Veterinary Anatomy, vol. 3, 2nd edn (Done, S. H., P. C. Goody, S. A.

266 Evans, and N. C. Stickland eds). London: Mosby - Elsevier.

267 Dyce, K. M., W. O. Sack, and C. J. G. Wensing, 2010: The Hindlimb of the Dog and Cat.

268 In: Textbook of Veterinary Anatomy, 4th edn (Dyce, K. M., W. O. Sack, and C. J. G.

269 Wensing eds). Saunders - Elsevier.

270 Evans, H. E., 1993: Arthrology. In: Miller's Anatomy of the Dog, 3rd edn (Evans, H. E.

271 ed). London: W. B. Saunders Company. 
272 Evans, H. E., and A. deLahunta, 1996: The Skeletal and Muscular Systems. In: Miller's

273 Guide to the Dissection of the Dog, 4th edn (Evans, H. E., and A. deLahunta eds).

274 London: W. B. Saunders Company.

275 Ginja, M. M., A. M. Silvestre, J. M. Gonzalo-Orden, and A. J. Ferreira, 2010: Diagnosis, 276 genetic control and preventive management of canine hip dysplasia: a review. Vet. J. $277 \quad \mathbf{1 8 4}, 269-276$.

278 Holsworth, I. G., K. S. Schulz, P. H. Kass, W. E. Scherrer, B. S. Beale, J. L. Cook, and

279 W. J. Hornof, 2005: Comparison of arthroscopic and radiographic abnormalities in 280 the hip joints of juvenile dogs with hip dysplasia. J. Am. Vet. Med. Assoc. 227, 281 1091-1094.

282 Jones, D. G. C., 1985: Conditions of the canine hip joint. Brit. Vet. J. 114, 554-563.

283 Liebich, H.-G., and H. E. König, 2001: Hinter- oder Beckengliedmaßen (Membra 284 pelvina). In: Anatomie der Haussäugetiere - Lehrbuch und Farbatlas für Studium 285 und Praxis (König, H. E., and H.-G. Liebich eds). Stuttgart: Schattauer.

286 Liebich, H.-G., H. E. König, and J. Maierl, 2004: Hindlimb or Pelvic Limb (Membra 287 pelvina). In: Veterinary Anatomy of Domestic Animals - Textbook and Colour Atlas 288 (König, H. E., and H.-G. Liebich eds). Stuttgart: Schattauer.

289 Lust, G., 1997: An overview of the pathogenesis of canine hip dysplasia. J. Am. Vet. $290 \quad$ Med. Assoc. 210, 1443-1445.

291 Lust, G., and B. A. Summers, 1981: Early, asymptomatic stage of degenerative joint 292 disease in canine hip joints. Am. J. Vet. Res. 42, 1849-1855. 
293 Lust, G., W. T. Beilman, D. J. Dueland, and P. W. Farrell, 1980: Intra-articular volume 294 and hip joint instability in dogs with hip dysplasia. J. Bone Joint Surg. Am. 62, 576$295 \quad 582$.

296 Lust, G., W. T. Beilman, V. T. Rendano, 1980: A relationship between degree of laxity 297 and synovial fluid volume in coxofemoral joints of dogs predisposed for hip 298 dysplasia. Am. J. Vet. Res. 41, 55-60.

299 Mande, J. D., P. M. F. Mbithi, S. W. Mbugua, I. B. J. Buoro, and P. K. Gathumbi, 2003:

300 Volume of the ligamentum capitis femoris in osteoarthritic hip joints of adult dogs. J. 301 S. Afr. Vet. Assoc. 74, 11-13.

302 Nickel, R., A. Schummer, E. Seiferle, J. Frewein, H. Wilkens, and K. H. Wille, 1986: The 303 Locomotor System of the Domestic Animals. In: The Anatomy of the Domestic 304 Animals, vol. 1 (Nickel, R., A. Schummer, and E. Seiferle eds). Berlin: Verlag Paul 305 Parey.

306 Popesko, P., 1982: Hond. In: Topografisch-anatomische Atlas van de Huisdieren 307 (Popesko, P. ed). Antwerp: Bohn Scheltema \& Holkema.

308 Salomon, F. V., 2005: Bewegungsapparat. In: Anatomie für die Tiermedizin (Salomon F. 309 V., H. Geyer, and U. Gille eds). Stuttgart: Enke Verlag.

310 Schoenecker, P. L., P. A. Lesker, and K. Ogata, 1984: A dynamic canine model of hip 311 dysplasia: Gross and histological pathology, and the effect of position of 312 immobilization on capital femoral epiphyseal blood flow. J. Bone Joint Surg. 66, $313 \quad 1281-1288$. 
314 Sisson, S., 1975: Carnivore Syndesmology. In: Sisson and Grossman's The Anatomy of

315 the Domestic Animals, 5th edn (Getty, R., C. E. Rosenbaum, N. G. Ghoshal, and D.

316 Hillmann eds). London: W. B. Saunders Company.

317 World Association of Veterinary Anatomists, 2012: Nomina Anatomica Veterinaria, 5th

318 edn (revised edition). Hamburg, Columbia, Ghent, Sapporo. Available at 319 http://www.wava-amav.org (accessed 27 June 2014).

320 Zietzschmann, O., 1974: Das Skeletsystem - Der Passive Bewegungsapparat. In:

321 Handbuch der Vergleichenden Anatomie der Haustiere (Ellenberger, W., H. Baum,

322 O. Zietzschmann, E. Ackerknecht, and H. Grau eds). Berlin: Springer-Verlag. 


\section{Tables}

324 Table 1. Breed and weight distribution of the examined dogs

\begin{tabular}{|l|c|l|}
\hline Breed & $\begin{array}{c}\text { Number of dogs } \\
\text { examined }\end{array}$ & $\begin{array}{l}\text { Mean weight } \pm \text { standard } \\
\text { deviation (range) in kg }\end{array}$ \\
\hline American Staffordshire Terrier & 5 & $24.8 \pm 4.1(20.5-31.5)$ \\
Beauceron & 1 & 32.0 \\
Belgian Malinois & 1 & 20.0 \\
Belgian Tervuren & 1 & 35.0 \\
Berner Sennen & 1 & 32.0 \\
Cairn Terrier & 1 & 9.0 \\
English Bulldog & 1 & 23.5 \\
English Cocker Spaniel & 1 & 20.0 \\
German Shepherd Dog & 3 & $29.7 \pm 1.8(28.0-31.5)$ \\
Golden Retriever & 1 & 37.0 \\
Groenendaler & 2 & $31.5 \pm 4.2(28.5-34.5)$ \\
Jack Russell Terrier & 6 & $8.1 \pm 2.1(4.5-10.5)$ \\
Labrador Retriever & 3 & $26.5 \pm 0.9(25.5-27.0)$ \\
Miniature Pinscher & 1 & 10.0 \\
Mongrel & 10 & $16.1 \pm 10.1(7.0-32.0)$ \\
Rottweiler & 3 & $38.5 \pm 7.4(33.5-47.0)$ \\
\hline
\end{tabular}

326 Table 2. Weight, volume and length of the ligament of the femoral head in the examined

\section{7 dog breeds}

\begin{tabular}{|l|c|l|l|l|}
\hline Breed & $\begin{array}{l}\text { Number } \\
\text { of joints } \\
\text { examined }\end{array}$ & $\begin{array}{l}\text { Mean weight } \pm \text { standard } \\
\text { deviation (range) in g }\end{array}$ & $\begin{array}{l}\text { Mean volume } \pm \text { standard } \\
\text { deviation (range) in } \mathrm{cm}^{3}\end{array}$ & $\begin{array}{l}\text { Mean length } \pm \text { standard } \\
\text { deviation (range) in mm }\end{array}$ \\
\hline American Staffordshire Terrier & 10 & $0.72 \pm 0.09(0.60-0.90)$ & $0.63 \pm 0.10(0.45-0.80)$ & $15.08 \pm 3.27(8.92-19.14)$ \\
Beauceron & 2 & $1.07 \pm 0.09(1.00-1.13)$ & $0.99 \pm 0.01(0.98-0.99)$ & $14.90 \pm 0.53(14.52-15.27)$ \\
Belgian Malinois & 1 & 0.72 & 0.70 & 12.76 \\
Belgian Tervuren & 1 & 1.46 & 1.38 & 12.55 \\
Berner Sennen & 2 & $1.12 \pm 0.07(1.07-1.17)$ & $1.01 \pm 0.16(0.90-1.12)$ & $13.97 \pm 0.18(13.84-14.10)$ \\
Cairn Terrier & 2 & $0.25 \pm 0.04(0.22-0.27)$ & - & - \\
English Bulldog & 1 & 0.41 & 0.38 & - \\
English Cocker Spaniel & 2 & $0.39 \pm 0.04(0.36-0.41)$ & $0.31 \pm 0.01(0.30-0.32)$ & $17.14 \pm 6.14(12.80-21.48)$ \\
German Shepherd Dog & 6 & $1.00 \pm 0.13(0.79-1.17)$ & $0.90 \pm 0.14(0.70-1.10)$ & $14.34 \pm 1.19(13.03-15.90)$ \\
Golden Retriever & 2 & $0.93 \pm 0.01(0.92-0.94)$ & $0.99 \pm 0.01(0.98-1.00)$ & $15.06 \pm 1.80(13.78-16.33)$ \\
Groenendaler & 4 & $0.94 \pm 0.29(0.70-1.33)$ & $0.79 \pm 0.23(0.60-1.10)$ & $14.47 \pm 1.17(13.64-15.30)$ \\
Jack Russell Terrier & 10 & $0.19 \pm 0.08(0.09-0.33)$ & $0.16 \pm 0.05(0.08-0.24)$ & $11.06 \pm 3.20(7.24-18.03)$ \\
Labrador Retriever & 5 & $0.63 \pm 0.10(0.51-0.76)$ & $0.59 \pm 0.08(0.50-0.70)$ & $16.46 \pm 3.00(12.22-18.67)$ \\
Miniature Pinscher & 1 & 0.16 & 0.10 & - \\
Mongrel & 17 & $0.52 \pm 0.35(0.18-1.10)$ & $0.43 \pm 0.31(0.10-1.00)$ & $12.70 \pm 4.37(6.98-19.69)$ \\
Rottweiler & 6 & $1.20 \pm 0.44(0.82-1.79)$ & $1.13 \pm 0.37(0.80-1.62)$ & $16.15 \pm 5.67(9.62-23.70)$ \\
\hline
\end{tabular}


330 Table 3. Length of the accessory ligament of the femoral head in the examined dog

331 breeds, from its branching origin on the ligament of the femoral head to its attachment on

332 the pelvis

\begin{tabular}{|l|c|l|}
\hline Breed & $\begin{array}{c}\text { Number of joints } \\
\text { examined }\end{array}$ & $\begin{array}{l}\text { Mean length } \pm \text { standard } \\
\text { deviation (range) in mm }\end{array}$ \\
\hline American Staffordshire Terrier & 10 & $13.37 \pm 3.11(8.70-18.22)$ \\
Beauceron & 2 & $15.25 \pm 0.16(15.13-15.36)$ \\
Belgian Malinois & 1 & 10.37 \\
Belgian Tervuren & 1 & 15.23 \\
Berner Sennen & 2 & $14.62 \pm 1.04(13.88-15.35)$ \\
English Bulldog & 1 & 13.38 \\
English Cocker Spaniel & 2 & $11.86 \pm 1.41(10.86-12.85)$ \\
German Shepherd Dog & 6 & $17.19 \pm 2.44(12.55-19.12)$ \\
Golden Retriever & 2 & $10.55 \pm 0.94(9.88-11.21)$ \\
Groenendaler & 4 & $13.69 \pm 0.75(12.72-14.56)$ \\
Jack Russell Terrier & 7 & $9.15 \pm 2.87(4.47-12.62)$ \\
Labrador Retriever & 4 & $11.65 \pm 1.45(9.50-12.58)$ \\
Mongrel & 15 & $12.35 \pm 3.17(8.03-18.09)$ \\
Rottweiler & 6 & $17.13 \pm 1.83(15.43-19.85)$ \\
\hline
\end{tabular}

333

334 


\section{Figures}

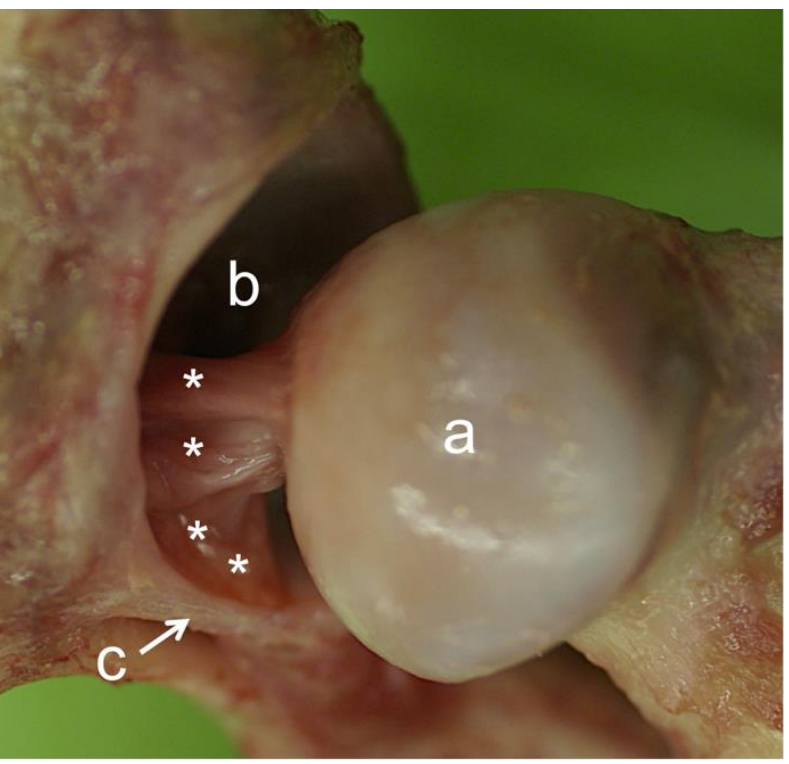

337 Fig. 1. Cranioventral view of a left canine hip joint showing the branched, fan-shaped

338 ligament of the femoral head (asterisks) originating on the head of the femur (a) and

339 attaching to the acetabulum (b) and the transverse acetabular ligament (c).

340

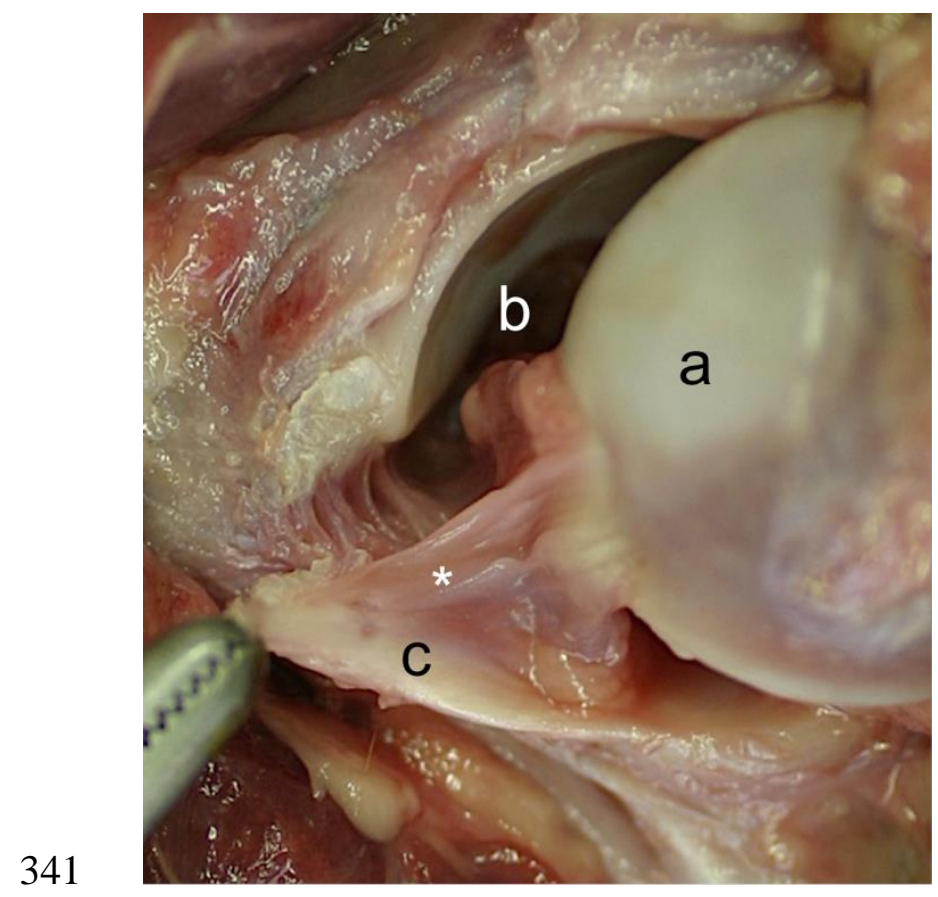


342 Fig. 2. Lateroventral view of a left canine hip joint, formed between the femoral head (a)

343 and the acetabulum (b), demonstrating the strand of the ligament of the femoral head

344 (asterisk) that attaches to the transverse acetabular ligament (c). The latter ligament has

345 been transected at its cranial insertion and is retracted by means of a forceps.

346

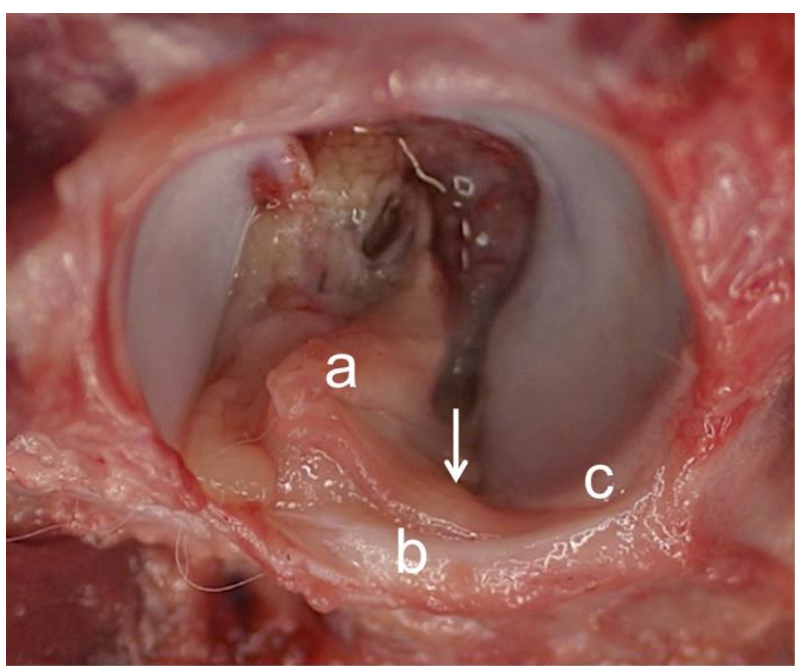

348 Fig. 3. Lateral view of a left canine acetabulum showing the major strand (a) of the

349 ligament of the femoral head attaching to the acetabular fossa, and an additional strand

350 (arrow) coursing in caudal direction between the transverse acetabular ligament (b) and

351 the caudoventral border of the acetabulum (c). 


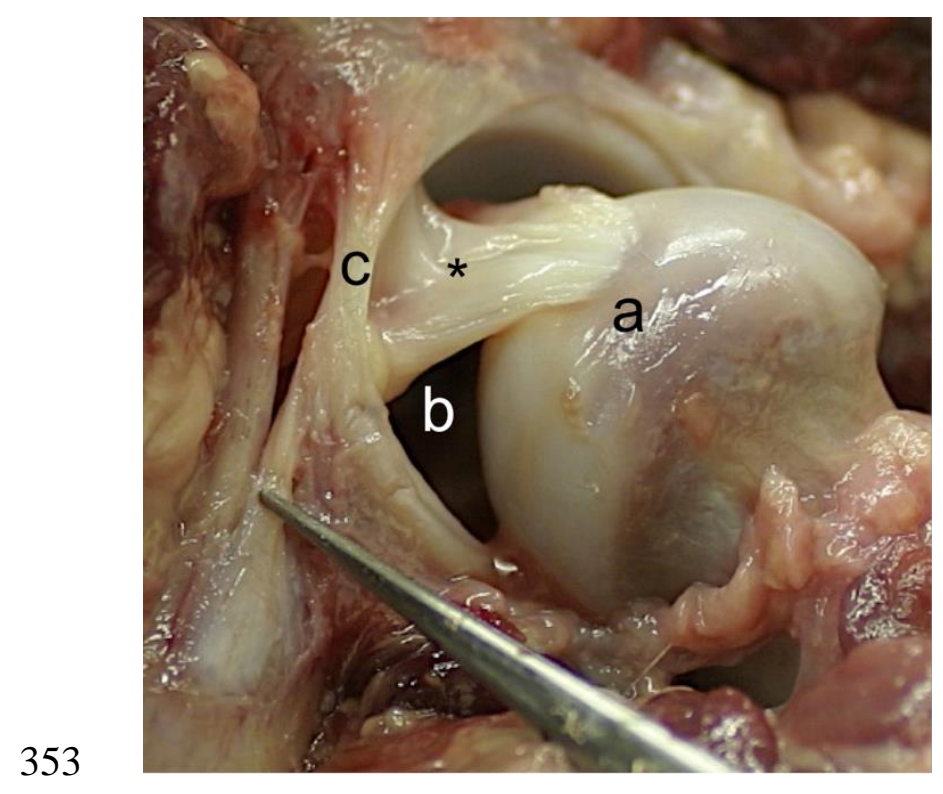

354 Fig. 4. Caudoventral view of a left canine hip joint. The ligament of the femoral head

355 (asterisk) connects the head of the femur (a) not only with the acetabulum (b), but also

356 with the transverse acetabular ligament (c). The forceps indicates the caudal part of the

357 accessory ligament of the femoral head that, after crossing the transverse acetabular

358 ligament dorsally, courses in caudal direction towards the cranioventral surface of the

359 body of the ischium.

360
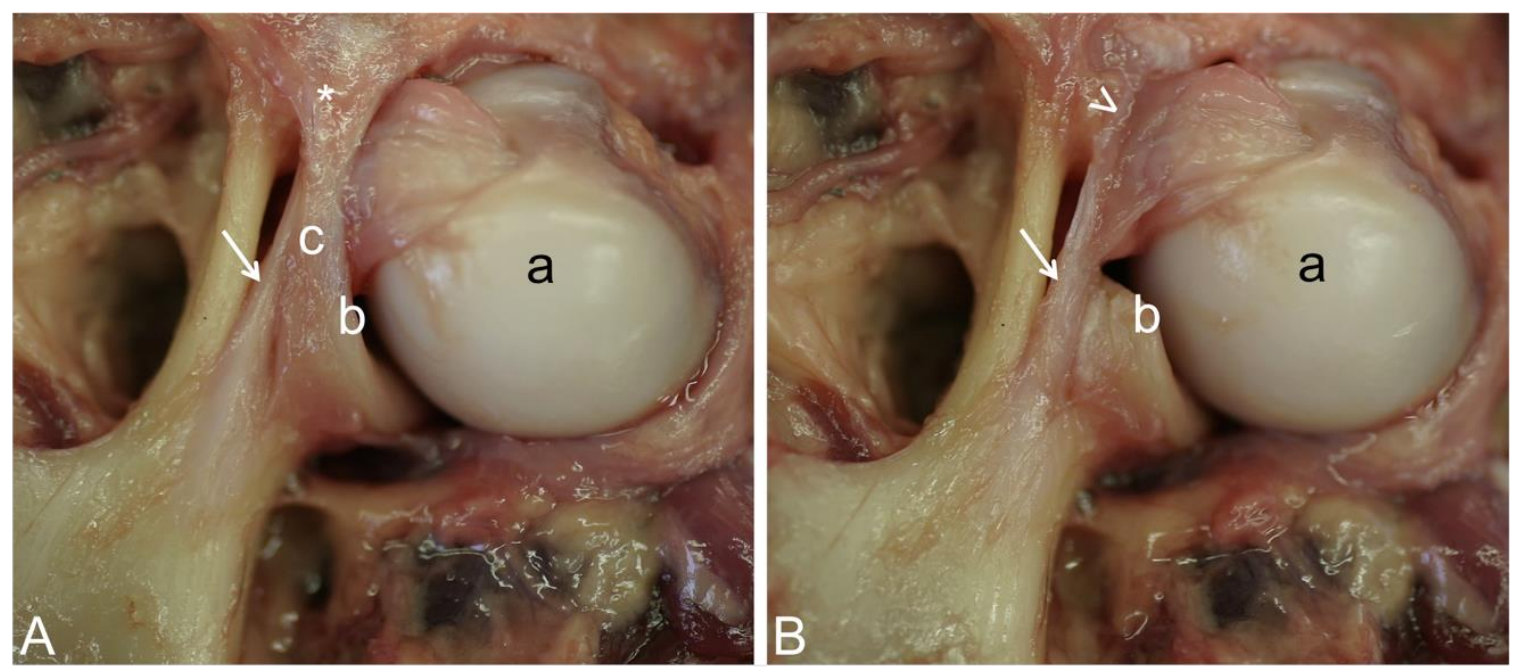
362 Fig. 5. Ventral views of a left canine hip joint showing the attachment of the femoral 363 head (a) to the acetabulum (b). Fig. 5A: The accessory ligament of the femoral head 364 crosses the cranial attachment (asterisk) of the transverse acetabular ligament (c) dorsally 365 and continues caudally outside the acetabulum (arrow). Fig. 5B: Resection of the 366 transverse acetabular ligament demonstrates that the accessory ligament inserts to the 367 cranial attachment site of the transverse acetabular ligament (arrowhead) and continues 368 caudally in the acetabular notch (arrow) to attach to the caudal elongation of the latter 369 structure on the cranioventral surface of the body of the ischium.

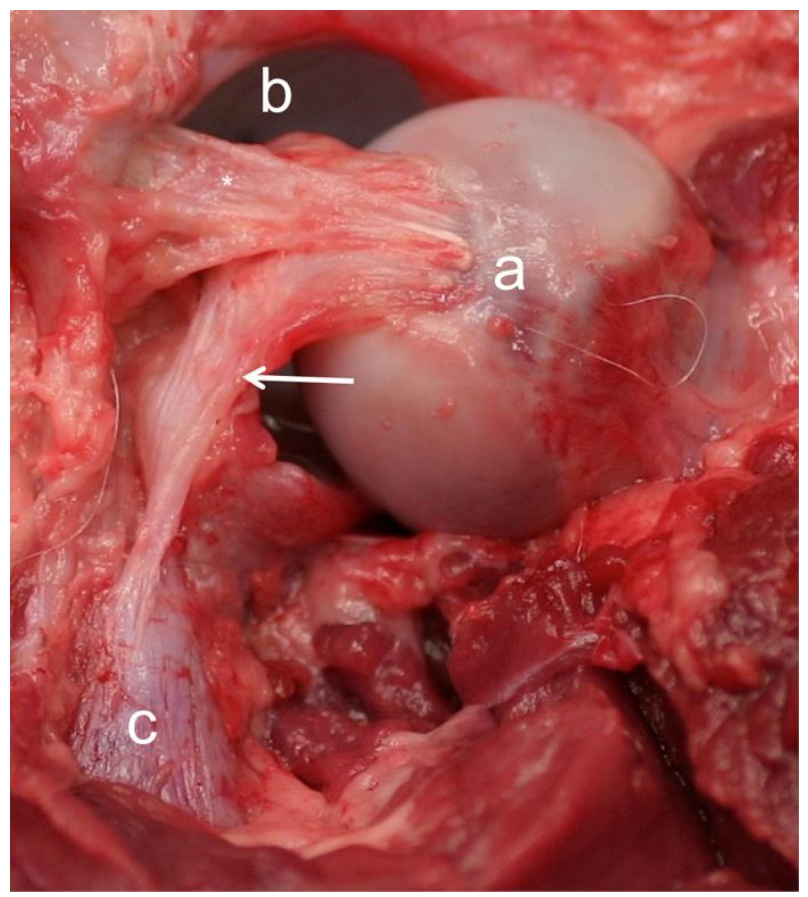

372 Fig. 6. Ventral view of a left canine hip joint, after removal of the transverse acetabular

373 ligament, showing the ligament of the femoral head (asterisk) which connects the femoral 374 head (a) with the acetabulum (b), and the accessory ligament of the femoral head (arrow)

375 which extends from the femoral head (a) in the caudal elongation of the acetabular notch 376 to the cranioventral surface of the body of the ischium (c). 


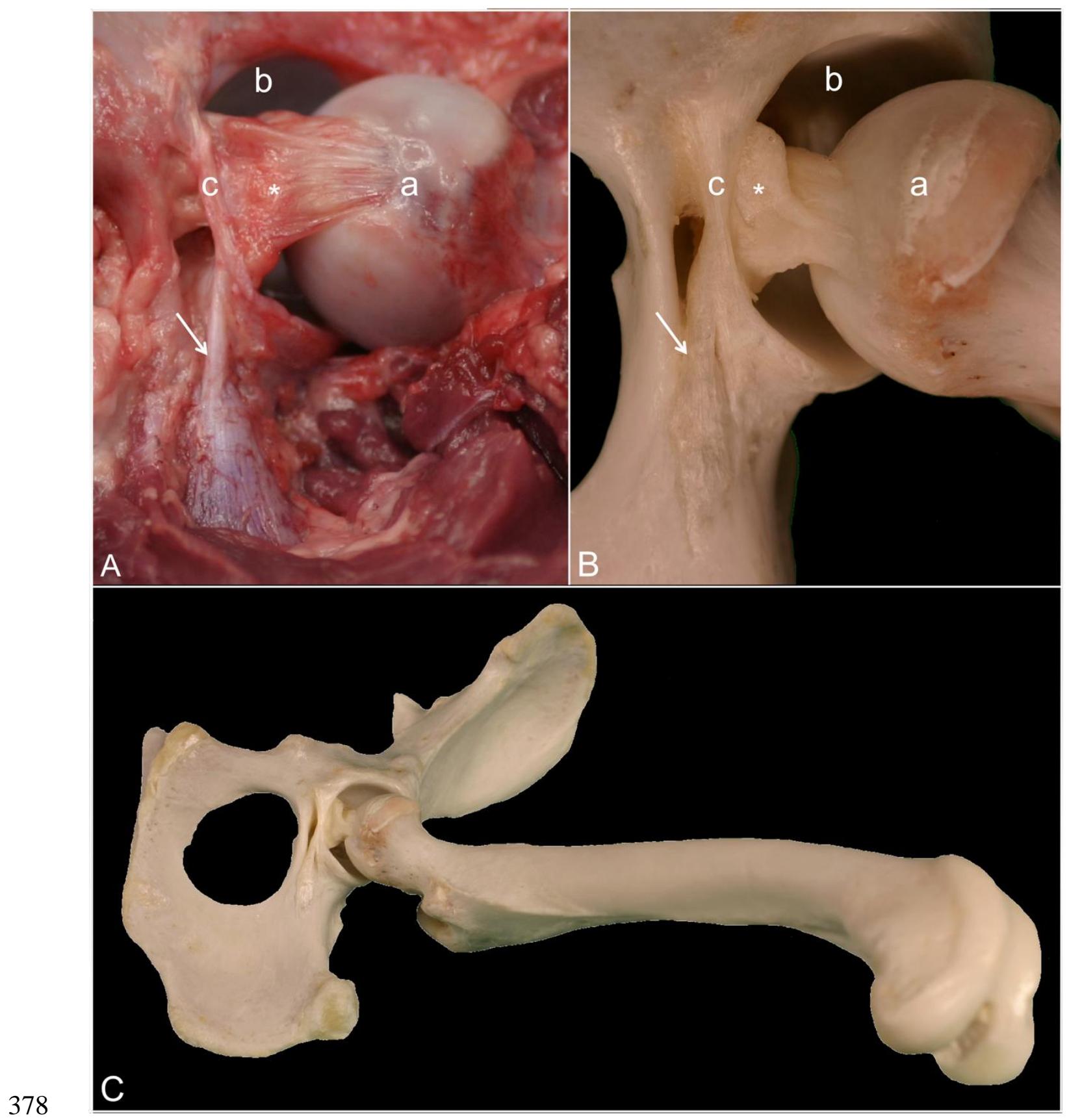

379 Fig. 7. Ventral views of a left canine hip joint. A. Dissected joint; B. Arthrologic

380 specimen; C. Overview of the arthrologic specimen. Femoral head (a), acetabulum (b),

381 transverse acetabular ligament (c), ligament of the femoral head (asterisk), accessory

382 ligament of the femoral head (arrow). 
383 